4-28-2021

\title{
Vegetation Type and Decomposition Priming Mediate Brackish Marsh Carbon Accumulation Under Interacting Facets of Global Change
}

Anthony J. Rietl

J. Patrick Megonigal

Ellen R. Herbert

Matthew L. Kirwan

Follow this and additional works at: https://scholarworks.wm.edu/vimsarticles

Part of the Earth Sciences Commons 


\section{Geophysical Research Letters}

\author{
RESEARCH LETTER \\ 10.1029/2020GL092051 \\ Key Points: \\ - Soil priming and species-specific \\ vegetation responses reduce \\ the impacts of elevated $\mathrm{CO}_{2}$ on \\ marsh sustainability and carbon \\ accumulation \\ - The relationship between sea level \\ rise and carbon accumulation is \\ driven by changes in soil volume \\ rather than carbon concentration \\ - The primary impact of elevated \\ $\mathrm{CO}_{2}$ on carbon accumulation is to \\ extend the lifespan of a marsh under \\ accelerated sea level rise
}

Supporting Information:

Supporting Information may be found in the online version of this article.

Correspondence to:

A. J. Rietl,

Anthony.Rietl@Wildlife.CA.gov

\section{Citation:}

Rietl, A. J., Megonigal, J. P., Herbert, E. R., \& Kirwan, M. L. (2021). Vegetation type and decomposition priming mediate brackish marsh carbon accumulation under interacting facets of global change. Geophysical Research Letters, 48, e2020GL092051. https://doi. org/10.1029/2020GL092051

Received 10 DEC 2020

Accepted 23 FEB 2021 (c) 2021. American Geophysical Union. All Rights Reserved.

\section{Vegetation Type and Decomposition Priming Mediate Brackish Marsh Carbon Accumulation Under Interacting Facets of Global Change}

\author{
Anthony J. Rietl $^{1,2}$ (D) J. Patrick Megonigal ${ }^{3}$ (D), Ellen R. Herbert ${ }^{1,4}$, and Matthew L. Kirwan ${ }^{1}$ (iD \\ ${ }^{1}$ Virginia Institute of Marine Science, William and Mary, Gloucester Point, VA, USA, ${ }^{2}$ Now at California Department \\ of Fish and Wildlife, West Sacramento, CA, USA, ${ }^{3}$ Smithsonian Environmental Research Center, Edgewater, MD, USA, \\ ${ }^{4}$ Now at Ducks Unlimited, Memphis, TN, USA
}

Abstract Coastal wetland carbon pools are globally important, but their response to interacting facets of global change remain unclear. Numerical models neglect species-specific vegetation responses to sea level rise (SLR) and elevated $\mathrm{CO}_{2}\left(e \mathrm{CO}_{2}\right)$ that are observed in field experiments, while field experiments cannot address the long-term feedbacks between flooding and soil growth that models show are important. Here, we present a novel numerical model of marsh carbon accumulation parameterized with empirical observations from a long-running $e \mathrm{CO}_{2}$ experiment in an organic rich, brackish marsh. Model results indicate that $e \mathrm{CO}_{2}$ and SLR interact synergistically to increase soil carbon burial, driven by shifts in plant community composition and soil volume expansion. However, newly parameterized interactions between plant biomass and decomposition (i.e. soil priming) reduce the impact of $e \mathrm{CO}_{2}$ on marsh survival, and by inference, the impact of $e \mathrm{CO}_{2}$ on soil carbon accumulation.

Plain Language Summary Coastal marshes are important globally because they tend to capture carbon from the atmosphere in their soils through the activities of plants, which could help moderate the effects of climate change. We developed a numerical computer model based on measurements from a long running elevated carbon dioxide experiment to predict how marshes will change in the future under differing global change scenarios, and how these changes will impact carbon in the soil. We found that elevated carbon dioxide allows marshes to survive faster rates of sea level rise, which in turn allows them to sequester carbon at faster rates. However, we also found that changes in plant communities and their effect on the decomposition of old plant material tends to reduce the overall impacts of elevated carbon dioxide on marsh survival and carbon capture.

\section{Introduction}

Coastal marshes and their carbon pools adapt to sea level rise largely through ecogeomorphic feedbacks in which increased flooding stimulates plant growth, mineral sediment deposition, and vertical soil development (D’Alpaos et al., 2007; Kirwan \& Megonigal, 2013; Marani et al., 2007; Morris et al., 2002). Because plant productivity and organic matter accumulation are inherently linked in anaerobic soils, these ecogeomorphic feedbacks also determine the amount of carbon that marsh soils accumulate through time (Gonneea et al., 2019; Kirwan \& Mudd, 2012). Recent work indicates that coastal wetlands are an important global carbon sink (Chmura, 2013; Hopkinson et al., 2012; Mcleod et al., 2011), and that carbon accumulation rates increase with accelerated sea level rise (Rogers et al., 2019; Wang et al., 2019). Coastal wetlands therefore potentially represent a unique negative carbon-climate feedback where carbon emissions lead to faster rates of sea level rise and enhanced carbon sequestration, making them an important tool toward mitigating changes in the Earth's climate (Crooks et al., 2011; Holmquist et al., 2018).

Nevertheless, the areal extent of coastal marshes has declined worldwide (Duarte, 2008), and there are concerns over the stability of coastal carbon pools in the face of interacting components of global change. Previous numerical modeling and stratigraphic observations suggest that the elevation of marshes and the size of their carbon pools increase with sea level rise until some threshold rate, beyond which they drown (Kirwan et al., 2010; Morris et al., 2002). Elevated $\mathrm{CO}_{2}\left(e \mathrm{CO}_{2}\right)$ increases marsh elevation gain in both short-term field experiments (Langley et al., 2009; Reef et al., 2017) and long-term modeling efforts (Ratliff et al., 2015), but how the interacting effects of SLR and $e \mathrm{CO}_{2}$ influence marsh resilience and carbon accumulation over 
decades to centuries is poorly understood. Empirical studies suggest that $e \mathrm{CO}_{2}$ increases soil carbon in terrestrial systems up to a saturation point (Heimann \& Reichstein, 2008; van Groenigen et al., 2014) and may make coastal marshes more resilient to SLR by increasing soil elevation via $\mathrm{C}_{3}$ plant productivity (Langley et al., 2009; Reef et al., 2017). However, increases in plant productivity may in turn lead to increased decay of older carbon via root-derived inputs of organic carbon and delivery of oxygen into an otherwise anaerobic soil, thereby decreasing the belowground carbon pool (Bernal et al., 2017; Jones et al., 2018; Mueller et al., 2015; Wolf et al., 2007). Vegetation growth leads to a persistent oxygenated zone in wetland sediments (Boaga et al., 2014; Marani et al., 2006), and root induced priming has been shown to be a key factor in regulating the direction of change in terrestrial carbon stocks (van Groenigen et al., 2014). However, the importance of priming relative to other drivers remains unexplored in coastal carbon pools.

Vegetation type may also be a strong driver of marsh carbon accumulation under SLR and $e \mathrm{CO}_{2}$. Due to the relatively stressful conditions in coastal marshes, many plant species have evolved to use the $\mathrm{C}_{4}$ photosynthetic pathway, which unlike $\mathrm{C}_{3}$ plants, utilizes a $\mathrm{CO}_{2}$ concentrating mechanism that negates $\mathrm{CO}_{2}$ limitation. Thus, as opposed to studies of the effects of $e \mathrm{CO}_{2}$ on elevation in $\mathrm{C}_{3}$ marshes, $\mathrm{C}_{4}$ vegetation has been shown to exhibit little to no response to $e \mathrm{CO}_{2}$ (Bernal et al., 2017; Morris \& Bowden, 1986; Mueller et al., 2015). Previous modeling neglects these differences in vegetation community response for simplicity and because of inherent difficulties separating the effects of $e \mathrm{CO}_{2}$ in mixed $\mathrm{C}_{3} / \mathrm{C}_{4}$ communities (Ratliff et al., 2015). Thus, a gap remains between short-term field experiments that show the importance of vegetation type, and long-term model experiments that suggest the importance of elevation dependent feedbacks. Here, we demonstrate with a novel soil-cohort model that $e \mathrm{CO}_{2}$ and SLR interact synergistically to increase soil carbon burial, driven by shifts in plant community composition, that facilitate an ever-expanding soil volume.

\section{Model Description}

Our model is designed to simulate changes in the elevation and carbon content of a soil column at a single point on a marsh surface through time, and in response to environmental drivers such as SLR and $e \mathrm{CO}_{2}$. Following previous soil-cohort approaches (Kirwan \& Mudd, 2012; Morris \& Bowden, 1986), soil cohorts are built annually through the deposition of mineral and organic sediment on the marsh surface and each cohort expands and contracts through time according to organic matter production and decomposition within the soil column. As in previous approaches, mineral deposition and organic matter production vary with the depth and duration of tidal inundation of the marsh surface, and organic matter production and decomposition decrease exponentially with depth below the soil surface. These models demonstrate that marsh elevations and carbon stocks equilibrate to moderate rates of SLR, whereby rates of soil formation equal rates of SLR, but drown under higher rates of SLR (Kirwan \& Mudd, 2012; Mudd et al., 2009).

Previous modeling efforts have focused on capturing only the most essential ecomorphodynamic interactions, neglecting many plant and microbial feedbacks that determine carbon preservation (Spivak et al., 2019). Here, we extend their utility by expanding the treatment of vegetation growth, belowground production, and decomposition to include nuanced feedbacks between vegetation type, $e \mathrm{CO}_{2}$, and organic matter priming. We consider two vegetation communities, a $\mathrm{C}_{4}$ marsh parameterized for Spartina patens and $\mathrm{C}_{3}$ marsh parameterized for Schoenopletus americanus, both common tidal marsh species across North America. At elevations where species overlap, our model creates mixed communities with productivity and decomposition parameterizations weighted according to the relative species distribution. Organic matter decomposition rates increase as aboveground biomass increases (Jones et al., 2018; Mueller et al., 2015), reflecting priming of soil organic matter decomposition associated with root exudation and turnover. The model is used to explore the response of marsh soil carbon to interactions between SLR and $e \mathrm{CO}_{2}$ using observations from the Smithsonian Global Change Research Wetland (GCReW), an organic rich microtidal marsh on a tributary of the Chesapeake Bay (USA) that includes the longest running $e \mathrm{CO}_{2}$ experiment in the world (Drake, 2014).

We parameterized our model using empirical data and a model hindcast to represent conditions similar to a high marsh at GCReW. The entire GCReW site receives negligible mineral sediment, allowing us to simplify lateral gradients in sediment supply, and isolate the effects of dynamic organic matter cycling as drivers of 

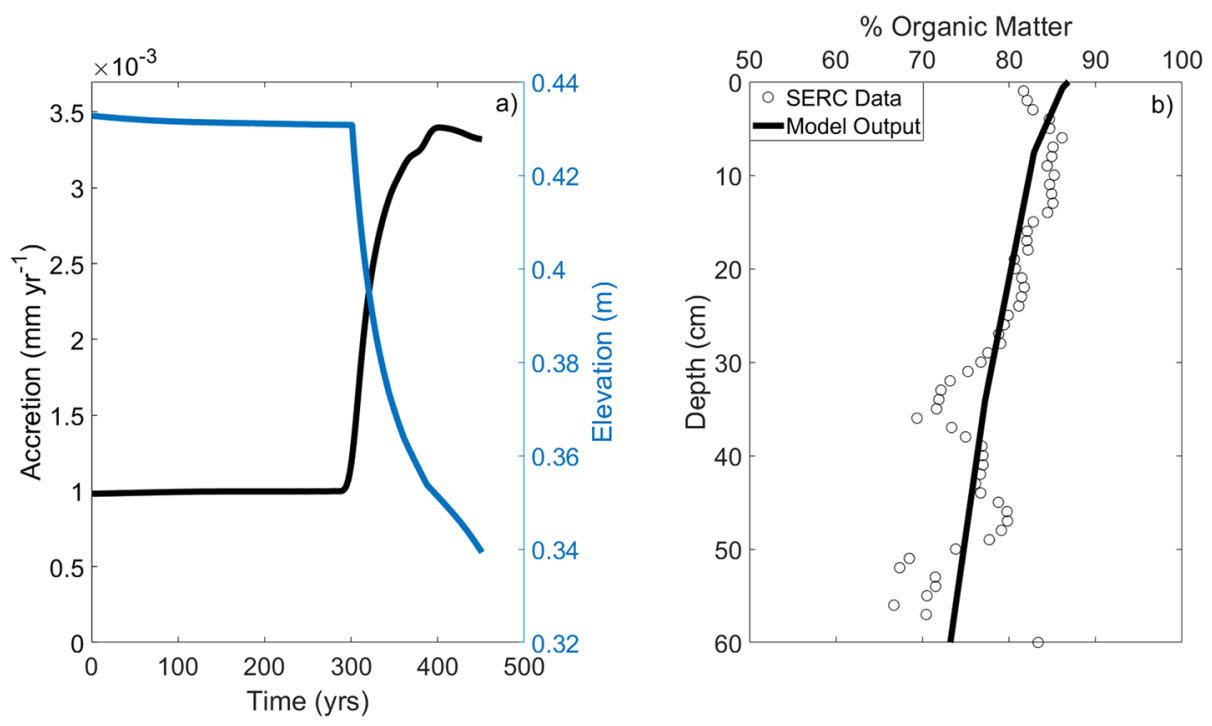

Figure 1. A hindcast model validation experiment in which an organic marsh equilibrated to a historic sea level rise rate of $1 \mathrm{~mm} \mathrm{yr}^{-1}$ was subjected to a modern rate of sea level rise at Kirkpatrick Marsh $\left(3.6 \mathrm{~mm} \mathrm{yr}^{-1}\right)$ for 150 years to recreate current conditions. (a) Accretion rate $\left(\mathrm{mm} \mathrm{yr}^{-1}\right.$; black line) and Elevation relative to sea level (m; blue line), (b) Percent organic matter (LOI) for model output (black line) and field data from Kirkpatrick Marsh (open circles).

marsh accretion and carbon accumulation. While other modeling experiments on the effects of $e \mathrm{CO}_{2}$ treated $\mathrm{C}_{3}$ and $\mathrm{C}_{4}$ species identically (Ratliff et al., 2015), long-term data at GCReW conclusively shows that $e \mathrm{CO}_{2}$ increases $\mathrm{C}_{3}$ biomass production with little effect on $\mathrm{C}_{4}$ biomass (Langley et al., 2009; Wolf et al., 2007). Our model therefore separates vegetation parameterizations for these fundamental plant functional types and additionally accounts for GCReW data that shows the $\mathrm{CO}_{2}$ fertilization effect on plant biomass is maximized at an intermediate inundation depth (Langley et al., 2013). Other empirical data used from the site includes tidal range, rooting depth profiles (Megonigal \& Holmquist, 2021), species-specific relationships between aboveground biomass and elevation (Byrd et al., 2017), their responses to $e \mathrm{CO}_{2}$ (Drake, 2014; Langley et al., 2009; van Groenigen et al., 2014), and the relationship between decomposition rate and aboveground biomass (Jones et al., 2018; Mueller et al., 2015; Table S1).

In order to estimate the parameters for which we did not have data, chiefly the decomposition and turnover rates of belowground biomass, we performed a model hindcast and adjusted unknown parameters until the model produced stratigraphic characteristics consistent with GCReW. This consisted of a spinup period that created an organic rich soil profile in equilibrium with the local late-Holocene rate of relative SLR $\left(\sim 1 \mathrm{~mm} \mathrm{yr}^{-1}\right)$, and then a 150-year model run under the historic local rate of SLR $\left(3.6 \mathrm{~mm} \mathrm{yr}^{-1}\right)$ observed in Annapolis, MD (NOAA, 2019). The model produced a final marsh elevation (0.34 m NAVD), accretion rate $\left(\sim 3.4 \mathrm{~mm} \mathrm{yr}^{-1}\right)$, and soil organic matter profile that are within the range of high marsh characteristics observed at GCReW today (Messerschmidt \& Kirwan, 2020; Figure 1). Also consistent with field observations at GCReW is the modeled loss of elevation relative to sea level (i.e., disequilibrium) (Figure 1), as evidenced by the increase in flood tolerant $\mathrm{C}_{3}$ low marsh species encroaching into $\mathrm{C}_{4}$ high marsh habitat over the past three decades (Lu et al., 2019). Taken together, these observations suggest that the model is generally capable of simulating soil-building processes at GCReW and other organic rich marshes.

\section{Results \& Conclusions}

To understand basic model behavior in a submerging marsh, we began our model experiments by subjecting a high elevation $\mathrm{C}_{4}$ marsh to a rate of SLR high enough to induce rapid drowning ( $25 \mathrm{~mm} \mathrm{yr}^{-1}$; Figure 2). In these model runs, simulations begin with a marsh elevation ( $0.43 \mathrm{~m}$ NAVD) and organic rich soil profile created during the model spin-up period under a $1 \mathrm{~mm} \mathrm{yr}^{-1}$ rate of SLR. Under ambient $\mathrm{CO}_{2}\left(a \mathrm{CO}_{2}\right)$, progressive inundation drives the conversion of $\mathrm{a}_{4}$ marsh to a mixed community dominated by $\mathrm{C}_{4}$ vegetation $(>50 \%)$, then to a mixed community dominated by $\mathrm{C}_{3}$ vegetation, and finally to a $\mathrm{C}_{3}$ marsh that submerges 

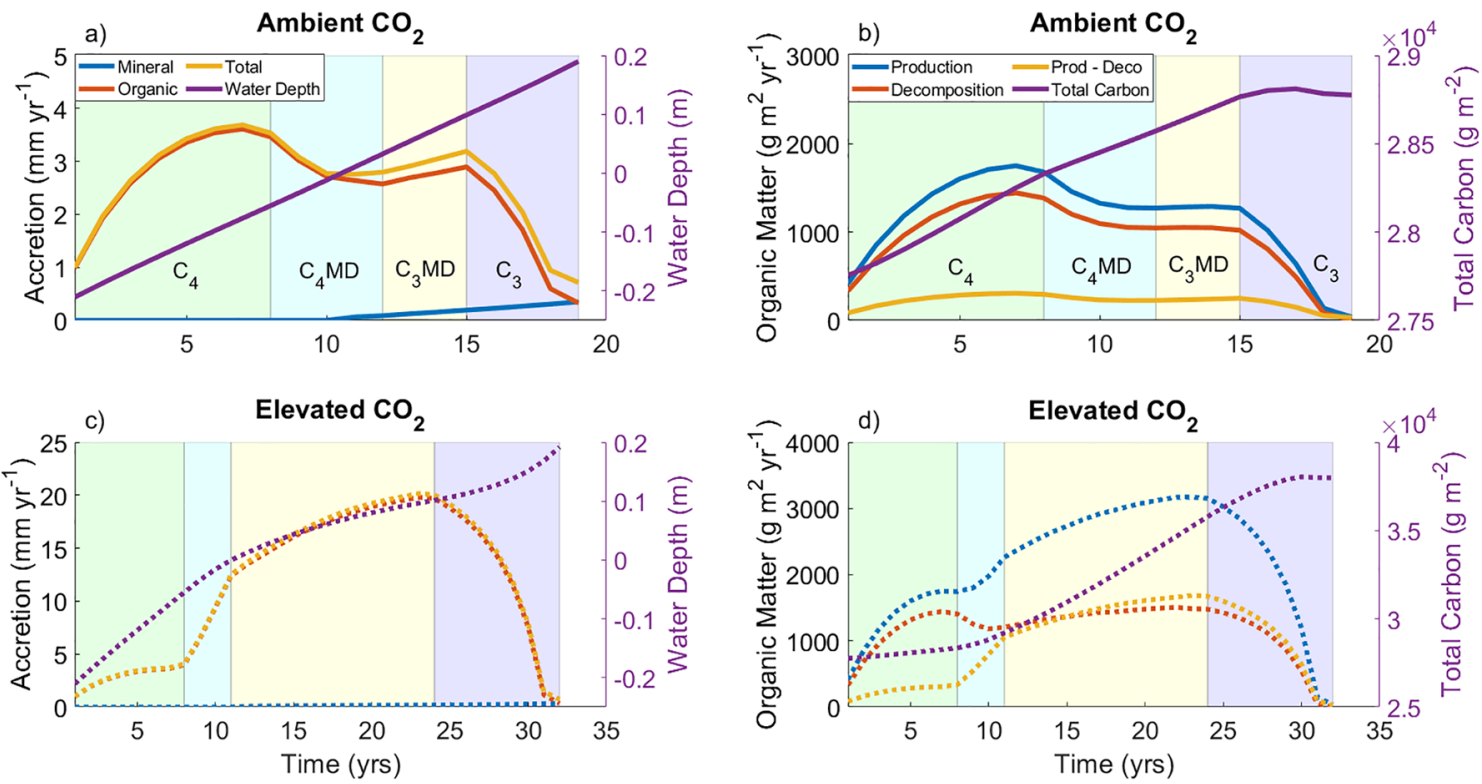

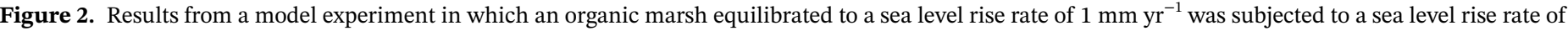
$25 \mathrm{~mm} \mathrm{yr}^{-1}$ in order to induce submergence under ambient and elevated $\mathrm{CO}_{2}$ conditions. Background panel colors represent vegetation types; a $\mathrm{C}_{4}$ (green), $\mathrm{C}_{4}$ dominant ( $>50 \%)$ mixed $\left(\mathrm{C}_{4} \mathrm{MD}\right.$; blue), $\mathrm{C}_{3}$ dominant ( $\left.>50 \%\right)$ mixed $\left(\mathrm{C}_{3} \mathrm{MD}\right.$; yellow), and $\mathrm{C}_{3}$ (purple) community. (a) Accretion rate (organic, mineral, and total) and water depth above marsh surface at mean high tide for a submerging marsh under ambient $\mathrm{CO}_{2}$ conditions, (b) Organic matter dynamics (production, decomposition, and net accumulation), and total carbon $\left(\mathrm{g} \mathrm{m}^{-2}\right)$ in the marsh soil profile for a submerging marsh under ambient $\mathrm{CO}_{2}$ conditions, (c) Accretion rate and water depth above marsh surface for a submerging marsh under elevated $\mathrm{CO}_{2}$ conditions, (d) Organic matter dynamics and total carbon in the soil profile for a submerging marsh under elevated $\mathrm{CO}_{2}$ conditions. Note the differing scales of the $x$-axes, and that negative water depths indicate a supratidal position of the marsh relative to mean high tide.

(Figure 2a). Accretion for the first 10 years is driven purely by organic inputs into a saturated high marsh that receives no tidal inundation. Although mineral accretion rates then increase through time, driven by longer and deeper flooding of the marsh surface, our parameterization (suspended sediment concentration $=5 \mathrm{mg} \mathrm{L}^{-1}$; tidal amplitude $=0.22 \mathrm{~m}$ ) limits mineral sediment deposition and ensures that organic matter accumulation dominates marsh elevation change. Under the modeled instantaneous increase in sea level rise rate (1-25 $\mathrm{mm} \mathrm{yr}^{-1}$ ), organic accretion rates initially increase from $\sim 1$ to $4 \mathrm{~mm} \mathrm{yr}^{-11}$ (Figure 2a) as production of $\mathrm{C}_{4}$ vegetation exceeds decomposition (Figure $2 \mathrm{~b}$ ). As vegetation shifts to more flood tolerant $\mathrm{C}_{3}$ vegetation with slower parameterized root turnover, organic accretion rates decline, and the marsh eventually drowns (Figure 2a). Total carbon summed over the entire profile increases throughout the experiment, even as instantaneous carbon accumulation rates fluctuate during conversion to $\mathrm{C}_{3}$ vegetation (Figure 2b).

Under $e \mathrm{CO}_{2}$ conditions, the model predicts qualitatively similar results (i.e., identical accretion rates for the $\mathrm{C}_{4}$ vegetation community, fluctuation in organic matter accumulation driven by vegetation type, and eventual submergence of the marsh platform). However, the positive effect of $e \mathrm{CO}_{2}$ on $\mathrm{C}_{3}$ vegetation growth allows the marsh to survive longer than under $a \mathrm{CO}_{2}$ (Figure 2c). Elevated $\mathrm{CO}_{2}$ prolonged a state change from tidal marsh to open water by over a decade under the accelerated rate of SLR applied in this modeling exercise $\left(25 \mathrm{~mm} \mathrm{yr}^{-1}\right)$, a response that would likely translate into several decades under most contemporary SLR scenarios. This behavior is driven by a bigger difference between enhanced production and decomposition than under $a \mathrm{CO}_{2}$ (Fig. 2d), and a more persistent mixed community where rapid $\mathrm{C}_{4}$ turnover accompanies $\mathrm{C}_{3}$ growth enhanced by $e \mathrm{CO}_{2}$, resulting in a synergistic enhancement of organic matter accumulation (Figure 2c). Total organic matter and carbon summed across the soil profile are higher under $e \mathrm{CO}_{2}$ (Figure 2d) than $a \mathrm{CO}_{2}$ (Figure 2b), indicating that the priming effect of plant biomass under $e \mathrm{CO}_{2}$ does not completely offset the increase in organic production.

Next, we conducted three separate model runs at $25 \mathrm{~mm} \mathrm{yr}^{-1}$ to explore how our novel parameterizations influence model behavior relative to approaches used in previous models, and in particular, the approaches 


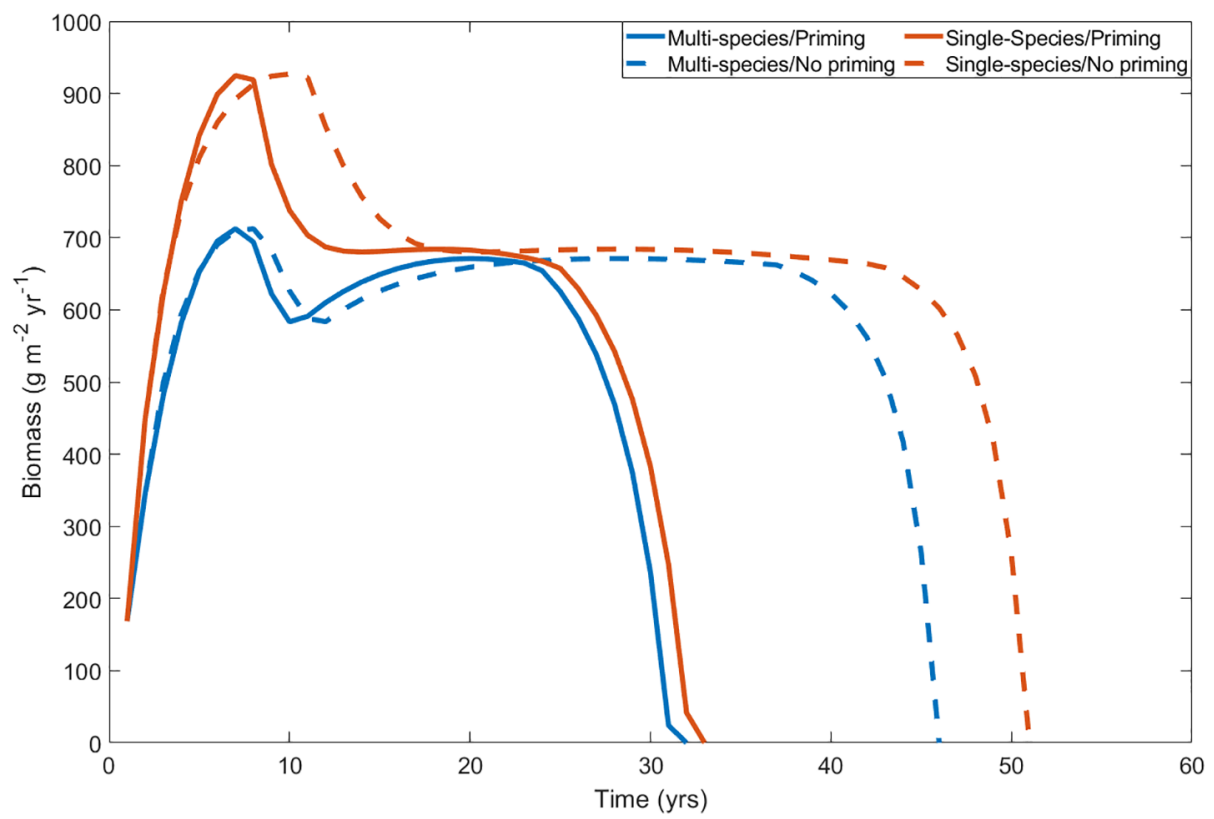

Figure 3. Aboveground biomass production through time for model experiments employing the methodological constraints of Ratliff et al. (2015) (a non-species-specific $\mathrm{CO}_{2}$ effect and no priming). Multi-species refers to our model parameterization that includes a positive $\mathrm{CO}_{2}$ effect on $\mathrm{C}_{3}$ vegetation but not $\mathrm{C}_{4}$ vegetation and priming refers to our model's incorporated priming effect on decomposition. Each model experiment began by subjecting an organic marsh equilibrated to a sea level rise rate of $1 \mathrm{~mm} \mathrm{yr}^{-1}$ to a sea level rise rate of $25 \mathrm{~mm} \mathrm{yr}^{-1}$.

used in the only other $e \mathrm{CO}_{2}$-informed tidal marsh model (Ratliff et al., 2015). Our model differs from previous models in two key ways: (a) we parameterize $\mathrm{C}_{3}$ and $\mathrm{C}_{4}$ species separately to include a $\mathrm{CO}_{2}$ fertilization effect on $\mathrm{C}_{3}$ species only, as opposed to the assumption that $e \mathrm{CO}_{2}$ affects all vegetation (Ratliff et al., 2015),

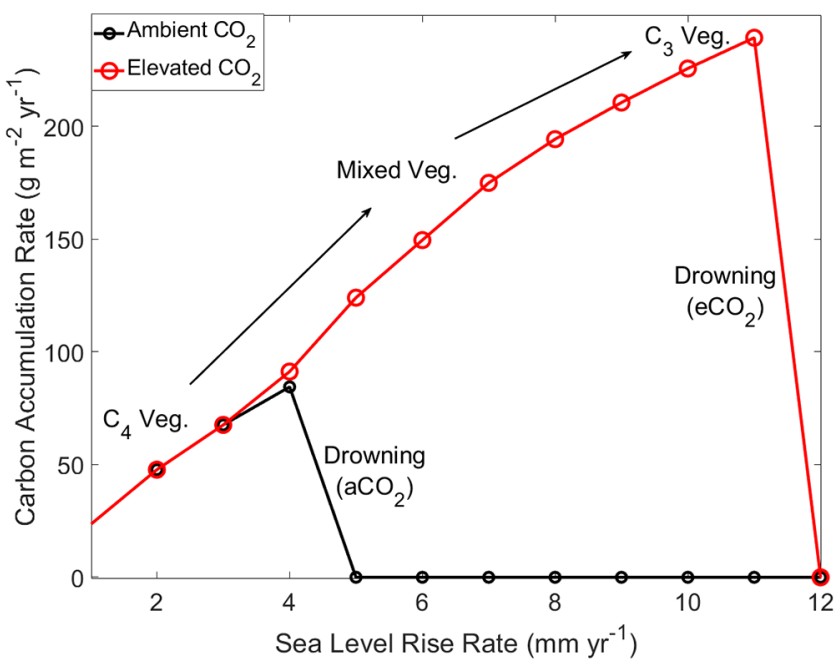

Figure 4. Results from model equilibration experiments in which a high elevation $\mathrm{C}_{4}$ marsh was subjected to progressively faster rates of sea level rise under ambient and elevated $\mathrm{CO}_{2}$. Carbon accumulation rates $\left(\mathrm{g} \mathrm{m}^{-2} \mathrm{yr}^{-1}\right)$ under ambient (black open circles) and elevated (red open circles) $\mathrm{CO}_{2}$ at sea level rise rates between 1 and $12 \mathrm{~mm} \mathrm{yr}^{-1}$. Marsh drowns when sea level rise exceeds $4 \mathrm{~mm} \mathrm{yr}^{-1}$ under $a \mathrm{CO}_{2}$ (black line) and $11 \mathrm{~mm} \mathrm{yr}^{-1}$ under $e \mathrm{CO}_{2}$ (red line). There is no effect of $e \mathrm{CO}_{2}$ on CAR at low sea level rise rates because the marsh equilibrates to elevations too high for $\mathrm{C}_{3}$ vegetation. and (b) our model incorporates a previously unexplored priming effect where decomposition fluctuates with plant productivity due to the introduction of fresh carbon, and/or radial oxygen loss from roots and rhizomes (Jones et al., 2018; Mueller et al., 2015). This means our decay rate is dynamic, changing throughout a model simulation as opposed to a static value. In these experiments, both species-specific $e \mathrm{CO}_{2}$ responses and organic matter priming lead to faster marsh drowning relative to the constraints of previous model (Figure 3). However, we also find that priming has a much stronger effect than the species-specific $e \mathrm{CO}_{2}$ parameterization (Figure 3). This surprising behavior is illustrated by the substantial difference in biomass produced between runs with and without species-specific effects, and yet little difference in the time until marsh submergence. These strikingly similar results occur because the increase in biomass of the $\mathrm{C}_{4}$ community under $e \mathrm{CO}_{2}$ is counterbalanced by an increase in decomposition in our model (Figure 3). This highlights an important aspect of our model, that production and decomposition are tightly coupled through time due to the plant-mediated priming effect and suggests that previous model results may overestimate the positive effects of $e \mathrm{CO}_{2}$ on marsh resilience (Ratliff et al., 2015).

To understand the interactive effect of $e \mathrm{CO}_{2}$ and SLR on marsh resilience and carbon accumulation rate, we subjected a high elevation $\mathrm{C}_{4}$ marsh to progressively faster rates of SLR and ran the model until it either equilibrated to the new rate of SLR or drowned. These simple model experiments illustrate that carbon accumulation rates (Figure 4) and total carbon in the soil profile (Figure 5) increase with increasing rates of 

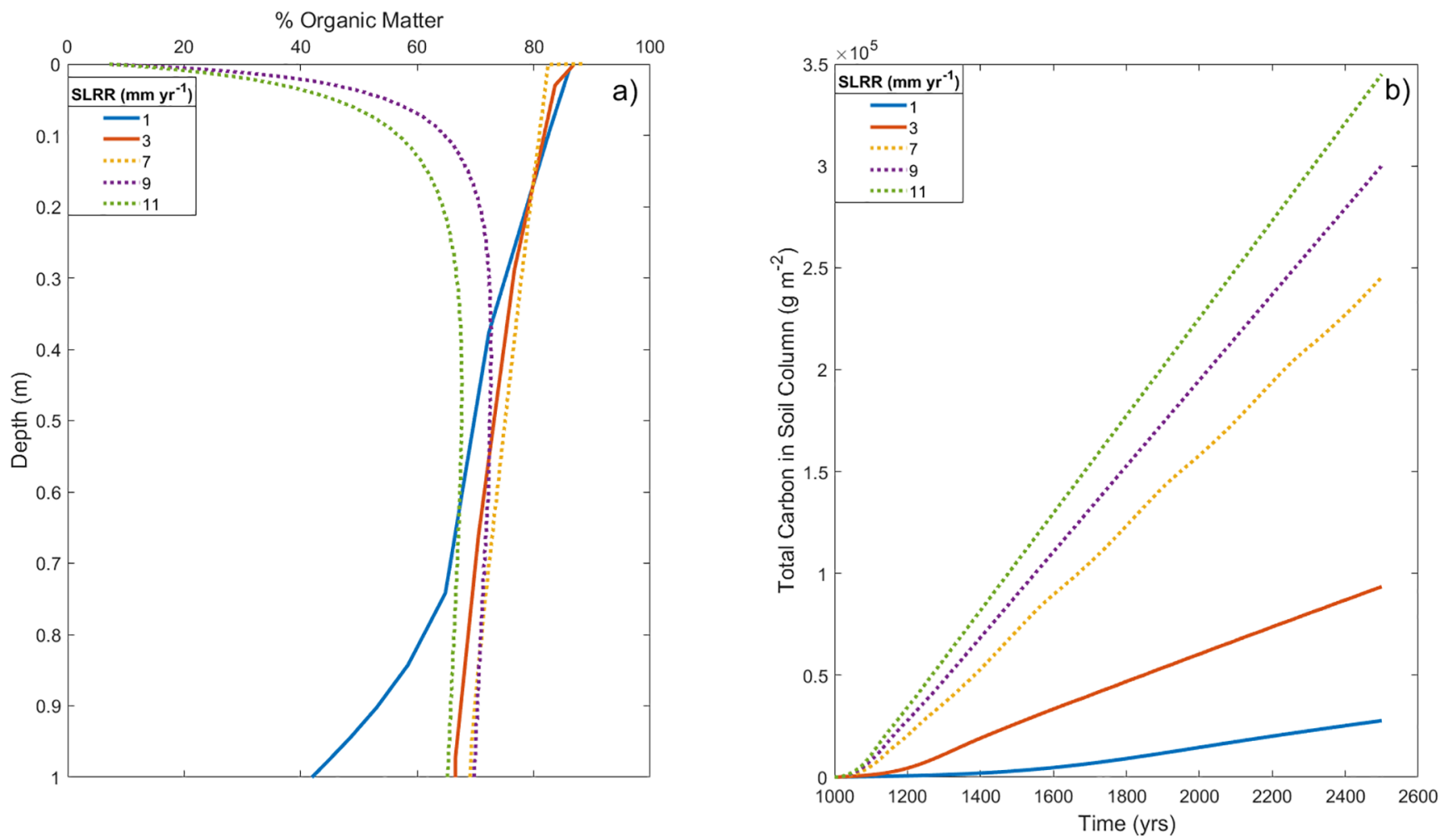

Figure 5. Results from model equilibration experiments in which a high elevation $\mathrm{C}_{4}$ marsh was subjected to progressively faster rates of sea level rise under ambient and elevated $\mathrm{CO}_{2}$. (a) Percent organic matter (LOI) for progressively faster sea level rise rates under ambient (solid lines) and elevated (dashed lines) $\mathrm{CO}_{2}$ conditions, (b) total carbon $\left(\mathrm{g} \mathrm{m}^{-2}\right)$ in the marsh soil profile for progressively faster sea level rise rates under ambient (solid lines) and elevated (dashed lines) $\mathrm{CO}_{2}$ conditions.

SLR until the point of marsh drowning. Interestingly, increases in soil carbon occur even as soils became more mineral rich, driven by surficial sediment deposition that increased with tidal inundation (Figure 5). Although this model behavior is consistent with faster burial and more efficient carbon preservation, we suggest it is more likely due to mineral deposition rates that increase more quickly than organic matter production rates, resulting in a relative decrease in percent organic matter (i.e., a decrease in carbon concentration). In contrast to terrestrial systems in which carbon accumulation is driven by changes in carbon concentration (Lu et al., 2019; Stewart et al., 2007), our results uniquely illustrate that marsh carbon pools are driven by changes in soil volume.

Our finding that carbon accumulation rates increase with the rate of SLR is consistent with previous modeling and stratigraphic observations that attribute accelerating rates of carbon accumulation to the reduction in carbon-sequestration saturation effects associated with an ever-expanding soil volume (Rogers et al., 2019). However, the explicit modeling of the interaction between $e \mathrm{CO}_{2}$ and SLR leads to new insights into the mechanisms responsible for increasing carbon accumulation. For example, based on inundation alone, organic matter production decreases as marshes transition from pure $\mathrm{C}_{4}$ to mixed communities (Figure 2a), but under $e \mathrm{CO}_{2} \mathrm{C}_{3}$ productivity more than compensates for the decline in productivity, and carbon accumulation rates increase (Figure $2 \mathrm{~d}$ ). This finding is qualitatively similar to previous modeling demonstrating that SLR and temperature warming lead to an increase in carbon accumulation rates (Kirwan \& Mudd, 2012), but in those model experiments warming did not enhance marsh persistence. Here, our results show that $e \mathrm{CO}_{2}$ extends marsh persistence where SLR drives the conversion of $\mathrm{C}_{4}$ vegetation to $\mathrm{C}_{3}$ vegetation that accumulates organic matter faster under $e \mathrm{CO}_{2}$ (Figure 4). In these experiments, marshes drown when SLR rates exceed 4 and $11 \mathrm{~mm} \mathrm{yr}^{-1}$ under $a \mathrm{CO}_{2}$ and $e \mathrm{CO}_{2}$ respectively. Although specific threshold rates of SLR and the quantitative effect of $e \mathrm{CO}_{2}$ on marsh accretion depend on model parameterizations, increased marsh resilience is generally consistent with empirical field experiments (Langley et al., 2009; Reef 
et al., 2017). Thus, the primary influence of $e \mathrm{CO}_{2}$ is to allow the marsh to survive faster rates of SLR, which in turn facilitates soil volume expansion, and faster carbon accumulation (Figure 4).

\section{Data Availability Statement}

The organic content and accretion rate data is available at https://doi.org/10.25573/serc.11914140.v1. The root distribution data is available at https://doi.org/10.25573/serc.13073249. All other data used to parameterize or test the numerical model is already published or otherwise publically available.

\section{References}

\section{Acknowledgments}

This material is based upon work supported by the US Department of Energy, Office of Science, Office of Biological and Environmental Research Program (DE-SC0014413 and DE-SC0019110), the National Science Foundation CAREER Program (EAR-1654374), and the Smithsonian Institution. We have uploaded organic content, accretion rate, and root distribution data used to paramterize and test the numerical model. This is contribution 3995 of the Virginia Institute of Marine Science, William \& Mary.
Bernal, B., Megonigal, J. P., \& Mozdzer, T. J. (2017). An Invasive wetland grass primes deep soil carbon pools. Global Change Biology, 23, 2104-2116. https://doi.org/10.1111/gcb.13539

Boaga, J., D'Alpaos, A., Cassiani, G., Marani, M., \& Putti, M. (2014). Plant-soil interactions in salt marsh environments: Experimental evidence from electrical resistivity tomography in the Venice Lagoon. Geophysical Research Letters, 41, 6160-6166. https://doi. $\operatorname{org} / 10.1002 / 2014$ gl060983

Byrd, K. B., Ballanti, L. R., Thomas, N. M., Nguyen, D. K., Holmquist, J. R., Simard, M., et al. (2017). Tidal marsh biomass field plot and remote sensing datasets for six regions in the conterminous United States (ver. 2.0, June, 2020). U.S. Geological Survey data release

Chmura, G. L. (2013). What do we need to assess the sustainability of the tidal salt marsh carbon sink? Ocean \& Coastal Management, 83 , 25-31. https://doi.org/10.1016/j.ocecoaman.2011.09.006

Crooks, S., Herr, D., Tamelander, J., Laffoley, D., \& Vandever, J. (2011). Mitigating climate change through restoration and management of coastal wetlands and near-shore marine ecosystems: challenges and opportunities (Environment Department Paper 121). Washington, DC: World Bank

D'Alpaos, A., Lanzoni, S., Marani, M., \& Rinaldo, A. (2007). Landscape evolution in tidal embayments: Modeling the interplay of erosion, sedimentation, and vegetation dynamics. Journal of Geophysical Research, 112, F1. https://doi.org/10.1029/2006jf000537

Drake, B. G. (2014). Rising sea level, temperature, and precipitation impact plant and ecosystem responses to elevated CO2on a Chesapeake Bay wetland: Review of a 28-year study. Global Change Biology, 20, 3329-3343. https://doi.org/10.1111/gcb.12631

Duarte, C. M., Dennison, W. C., Orth, R. J. W., \& Carruthers, T. J. B. (2008). The charisma of coastal ecosystems: Addressing the imbalance. Estuaries and Coasts: J CERF, 31, 233-238. https://doi.org/10.1007/s12237-008-9038-7

Gonneea, M. E., Maio, C. V., Kroeger, K. D., Hawkes, A. D., Mora, J., Sullivan, R., et al. (2019). Salt marsh ecosystem restructuring enhances elevation resilience and carbon storage during accelerating relative sea-level rise. Estuarine, Coastal and Shelf Science, 217, 56-68. https://doi.org/10.1016/j.ecss.2018.11.003

Heimann, M., \& Reichstein, M. (2008). Terrestrial ecosystem carbon dynamics and climate feedbacks. Nature, 451, 289-292. https://doi. org/10.1038/nature06591

Holmquist, J. R., Windham-Myers, L., Bliee, N., Crooks, S., Morris, J. T., Megonigal, J. P., et al. (2018). Accuracy and precision of tidal wetland soil carbon mapping in the conterminous United States. Scientific Reports, 8, 9478. https://doi.org/10.1038/s41598-018-33283-4

Hopkinson, C. S., Cai, W.-J., \& Hu, X. (2012). Carbon sequestration in wetland dominated coastal systems-a global sink of rapidly diminishing magnitude. Current Opinion in Environmental Sustainability, 4, 186-194. https://doi.org/10.1016/j.cosust.2012.03.005

Jones, S. F., Stagg, C. L., Krauss, K. W., \& Hester, M. W. (2018). Flooding alters plant-mediated carbon cycling independently of elevated atmospheric CO2 concentrations. Journal of Geophysical Research: Biogeosciences, 123, 1976-1987. https://doi.org/10.1029/2017jg004369

Kirwan, M. L., Guntenspergen, G. R., D'Alpaos, A., Morris, J. T., Mudd, S. M., \& Temmerman, S. (2010). Limits on the adaptability of coastal marshes to rising sea level. Geophysical Research Letters, 37. https://doi.org/10.1029/2010gl045489

Kirwan, M. L., \& Megonigal, J. P. (2013). Tidal wetland stability in the face of human impacts and sea-level rise. Nature, 504, 53-60. https:// doi.org/10.1038/nature12856

Kirwan, M. L., \& Mudd, S. M. (2012). Response of salt-marsh carbon accumulation to climate change. Nature, 489, 550-553. https://doi. org/10.1038/nature11440

Langley, J. A., McKee, K. L., Cahoon, D. R., Cherry, J. A., \& Megonigal, J. P. (2009). Elevated CO2 stimulates marsh elevation gain, counterbalancing sea-level rise. Proceedings of the National Academy of Sciences, 106, 6182-6186. https://doi.org/10.1073/pnas.0807695106

Langley, J. A., Mozdzer, T. J., Shepard, K. A., Hagerty, S. B., \& Megonigal, J. P. (2013). Tidal marsh plant responses to elevated $\mathrm{CO}_{2}$, nitrogen fertilization, and sea level rise. Global Change Biology, 19, 1495-1503.

Lu, M., Herbert, E. R., Langley, J. A., Kirwan, M. L., \& Megonigal, J. P. (2019). Nitrogen status regulates morphological adaptation of marsh plants to elevated CO2. Nature Climate Change, 9, 764-768. https://doi.org/10.1038/s41558-019-0582-x

Marani, M., D'Alpaos, A., Lanzoni, S., Carniello, L., \& Rinaldo, A. (2007). Biologically-controlled multiple equilibria of tidal landforms and the fate of the Venice lagoon. Geophysical Research Letters, 34, L11402. https://doi.org/10.1029/2007gl030178

Marani, M., Silvestri, S., Belluco, E., Ursino, N., Comerlati, A., Tosatto, O., \& Putti, M. (2006). Spatial organization and ecohydrological interactions in oxygen-limited vegetation ecosystems. Water Resources Research, 42, W06D06. https://doi.org/10.1029/2005wr004582

Mcleod, E., Chmura, G. L., Bouillon, S., Salm, R., Björk, M., Duarte, C. M., et al. (2011). A blueprint for blue carbon: toward an improved understanding of the role of vegetated coastal habitats in sequestering CO 2. Frontiers in Ecology and the Environment, 9, 552-560. https://doi.org/10.1890/110004

Megonigal, J. P., \& Holmquist, J. (2021). $1999 \mathrm{CO}_{2}$ x community deep root biomass. https://doi.org/10.25573/serc.13073249

Messerschmidt, T. C., \& Kirwan, M. L. (2020). Dataset: Soil properties and accretion rates of $C_{3}$ and $C_{4}$ marshes at the global change Research wetland. Edgewater, MD: figshare. Dataset. https://doi.org/10.25573/serc.11914140.v1

Morris, J. T., \& Bowden, W. B. (1986). A mechanistic, numerical model of sedimentation, mineralization, and decomposition for marsh sediments. Soil Science Society of America Journal, 50, 96-105. https://doi.org/10.2136/sssaj1986.03615995005000010019x

Morris, J. T., Sundareshwar, P. V., Nietch, C. T., Kjerfve, B., \& Cahoon, D. R. (2002). Responses of Coastal Wetlands to Rising Sea Level. Ecology, 83, 2869-2877. https://doi.org/10.1890/0012-9658(2002)083[2869:rocwtr]2.0.co;2 
Mudd, S. M., Howell, S. M., \& Morris, J. T. (2009). Impact of dynamic feedbacks between sedimentation, sea-level rise, and biomass production on near-surface marsh stratigraphy and carbon accumulation. Estuarine, Coastal and Shelf Science, 82, 377-389. https://doi. org/10.1016/j.ecss.2009.01.028

Mueller, P., Jensen, K., \& Megonigal, J. P. (2015). Plants mediate soil organic matter decomposition in response to sea level rise. Global Change Biology, 22, 404-414. https://doi.org/10.1111/gcb.13082

NOAA. (2019). Relative sea level trend for station 8575512. Annapolis, MD. Retrieved from https://tidesandcurrents.noaa.gov/sltrends/ sltrends_station.shtml?id=8575512

Ratliff, K. M., Braswell, A. E., \& Marani, M. (2015). Spatial response of coastal marshes to increased atmospheric CO2. Proceedings of the National Academy of Sciences of the United States of America, 112, 15580-15584. https://doi.org/10.1073/pnas.1516286112

Reef, R., Spencer, T., Moller, I., Lovelock, C. E., Christie, E. K., Mcivor, A. L., et al. (2017). The effects of elevated CO2and eutrophication on surface elevation gain in a European salt marsh. Global Change Biology, 23, 881-890. https://doi.org/10.1111/gcb.13396

Rogers, K., Kelleway, J. J., Saintilan, N., Megonigal, J. P., Adams, J. B., Holmquist, J. R., et al. (2019). Wetland carbon storage controlled by millennial-scale variation in relative sea-level rise. Nature, 567, 91-95. https://doi.org/10.1038/s41586-019-0951-7

Spivak, A. C., Sanderman, J., Bowen, J. L., Canuel, E. A., \& Hopkinson, C. S. (2019). Global-change controls on soil-carbon accumulation and loss in coastal vegetated ecosystems. Nature Geoscience, 12, 685-692. https://doi.org/10.1038/s41561-019-0435-2

Stewart, C. E., Paustian, K., Conant, R. T., Plante, A. F., \& Six, J. (2007). Soil carbon saturation: concept, evidence and evaluation. Biogeochemistry, 86, 19-31. https://doi.org/10.1007/s10533-007-9140-0

van Groenigen, K. J., Qi, X., Osenberg, C. W., Luo, Y., \& Hungate, B. A. (2014). Faster Decomposition Under Increased Atmospheric CO2 Limits Soil Carbon Storage. Science, 344, 508-509. https://doi.org/10.1126/science.1249534

Wang, F., Xiaoliang, L., Sanders, J. C., \& Tang, J. (2019). Tidal wetland resilience to sea level rise increases their carbon sequestration capacity in United States. Nature Communications, 10, 5434. https://doi.org/10.1038/s41467-019-13800-3

Wolf, A. A., Drake, B. G., Erickson, J. E., \& Megonigal, J. P. (2007). An oxygen-mediated positive feedback between elevated carbon dioxide and soil organic matter decomposition in a simulated anaerobic wetland. Global Change Biology, 13, 2036-2044. https://doi. org/10.1111/j.1365-2486.2007.01407.x

\section{References From the Supporting Information}

Agren, G. I., \& Ingestad, T. (1987). Root: Shoot ratio as a balance between nitrogen productivity and photosynthesis. Plant, Cell and Environment, 10, 579-586. https://doi.org/10.1111/1365-3040.ep11604105

Bradley, P. M., \& Morris, J. T. (1990). Influence of oxygen and sulfide concentration on nitrogen uptake kinetics in Spartina alterniflora. Ecology, 71, 282-287. https://doi.org/10.2307/1940267

Craft, C. B., Seneca, E. D., \& Broome, S. W. (1991). Loss on ignition and Kjeldahl digestion for estimating organic carbon and total nitrogen in estuarine marsh soils: calibration with dry combustion. Estuaries, 14, 175-179. https://doi.org/10.2307/1351691

Curtis, P. S., Balduman, L. M., Drake, B. G., \& Whigham, D. F. (1990). Elevated Atmospheric CO2 Effects on Belowground Processes in C3 and C4 Estuarine Marsh Communities. Ecology, 71, 2001-2006. https://doi.org/10.2307/1937608

Gill, R. A., \& Jackson, R. B. (2000). Global patterns of root turnover for terrestrial ecosystems. New Phytologist, 147, 13-31. https://doi. org/10.1046/j.1469-8137.2000.00681.x

Giurgevich, J. R., \& Dunn, E. L. (1981). A comparative analysis of the CO2 and water vapor responses of two Spartina species from Georgia coastal marshes. Estuarine, Coastal and Shelf Science, 12, 561-568. https://doi.org/10.1016/s0302-3524(81)80082-5

Gulde, S., Chung, H., Amelung, W., Chang, C., \& Six, J. (2008). Soil carbon saturation controls labile and stable carbon pool dynamics. Soil Science Society of America Journal, 72, 605-612. https://doi.org/10.2136/sssaj2007.0251

Hopkinson, C. S., Morris, J. T., Fagherazzi, S., Wollheim, W. M., \& Raymond, P. A. (2018). Lateral marsh edge erosion as a source of sediments for vertical marsh accretion. Journal of Geophysical Research: Biogeosciences, 123, 2444-2465. https://doi.org/10.1029/2017jg004358

Kirwan, M. L., \& Guntenspergen, G. R. (2015). Response of plant productivity to experimental flooding in a stable and a submerging marsh. Ecosystems, 18, 903-913. https://doi.org/10.1007/s10021-015-9870-0

Marani, M., D'Alpaos, A., Lanzoni, S., Carniello, L., \& Rinaldo, A. (2010). The importance of being coupled: Stable states and catastrophic shifts in tidal biomorphodynamics. Journal of Geophysical Research, 115, F4. https://doi.org/10.1029/2009jf001600

Morris, J. T., Barber, D. C., Callaway, J. C., Chambers, R., Hagen, S. C., Hopkinson, C. S., et al. (2016). Contributions of organic and inorganic matter to sediment volume and accretion in tidal wetlands at steady state. Earth's Future, 4, 110-121. https://doi. $\operatorname{org} / 10.1002 / 2015$ ef000334

Reynolds, H. L., \& D'Antonio, C. (1996). The ecological significance of plasticity in root weight ratio in response to nitrogen: Opinion. Plant and Soil, 185, 75-97. https://doi.org/10.1007/bf02257566

Reynolds, J. F., \& Thornley, J. H. M. (1982). A shoot: Root partitioning model. Annals of Botany, 49, 585-597. https://doi.org/10.1093/ oxfordjournals.aob.a086286

Van de Broek, M., Vandendriessche, C., Poppelmonde, D., Merckx, R., Temmerman, S., \& Govers, G. (2018). Long-term organic carbon sequestration in tidal marsh sediments is dominated by old-aged allochthonous inputs in a macrotidal estuary. Global Change Biology, 24, 2498-2512. https://doi.org/10.1111/gcb.14089 